\title{
PENGELOLAAN IN HOUSE JOURNAL PT BIO FARMA (PERSERO)
}

\author{
Shafira Yasmin Nandini ${ }^{1}$, Syauqy Lukman ${ }^{2}$ \\ ${ }^{1,2}$ Universitas Padjadjaran, Bandung, Indonesia
}

\begin{abstract}
ABSTRAK
Suatu perusahaan pada umumnya memiliki keinginan atau tujuan untuk maju, terus berkembang baik dalam maupun luar negeri. Untuk mencapai tujuan tersebut dibutuhkan dukungan dari stakeholder perusahaan. Public relations sebagai salah satu profesi yang memiliki peran penting dalam perusahaan turut memiliki tanggung jawab untuk mempererat hubungan internal perusahaan yang salah satunya dapat dicapai melalui media internal perusahaan atau in house journal. PT Bio Farma (Persero) dalam membangun hubungan internalnya dibantu oleh Seksi Hubungan Internal dalam Bagian Corporate Communications. PT Bio Farma (Persero) memiliki in house journal bernama BioMagz yang dibuat untuk mengedukasi karyawan mengenai perusahaan agar memiliki pengetahuan lebih banyak mengenai tempat mereka bekerja, agar menambah rasa bangga dan cinta terhadap perusahaan. Tujuan penelitian ini adalah mengetahui seluruh proses pengelolaan BioMagz. Penelitian ini bersifat kualitatif dengan metode deskriptif. Hasil dari penelitian ini terdapat empat komponen dalam pengelolaan in-house journal, yaitu perencanaan, alur pengumpulan konten/isi dan proses pra-cetak hingga tahap pencetakan. BioMagz memiliki susunan redaksi yang terdiri dari staff Corporate Communications dan terdiri dari 10 rubrik. Isi artikel dari rubrik diperoleh melalui wawancara, observasi dan studi pustaka. Terdapat alur kerja yang pasti dalam pembuatan setiap edisi dari BioMagz sebelum akhirnya masuk tahap percetakan dan sirkulasi. Kesimpulannya adalah BioMagz berbentuk majalah, terbit setiap 3 bulan sekali dan termasuk kedalam in house journal yang ideal, namun dalam prakteknya masih ada alur kerja yang berantakan dan terdapat masalah dalam proses distribusi. Saran yang dapat diberikan adalah agar kembali melakukan evaluasi terhadap tahapan kerja dan jobdesc dari redaksi dan kuantitas dari BioMagz ditambah sehingga tersebar kepada seluruh karyawan.
\end{abstract}

Kata-kata Kunci: House Journal, In House Journal, Public Relations, Hubungan Internal

\section{IN-HOUSE JOURNAL MANAGEMENT IN PT BIO FARMA (PERSERO)}

\section{ABSTRACT}

A company, in general, must have a goal to continue developing, and to achieve this goal, the support of stakeholders of the company is needed. Public relations as one profession with an important role in the company to strengthen the company's internal relations, one of which can be achieved through internal media or in-house journal. Likewise, PT Bio Farma (Persero), which is developing its internal relations is assisted by the Internal Relations Section in the Corporate Communications Section. PT Bio Farma (Persero) has an in-house journal called BioMagz created to educate employees about the company to have more knowledge about where they work, which ultimately adds to their sense of pride and love for the company. The purpose of this study is to find out the entire process of managing BioMagz. This research is qualitative with a descriptive method. The results of this study are that there are four components in managing in house journals; planning, content flow, pre-print process, and printing. BioMagz has an editorial structure consisting of Corporate 
Communications staff and managing 10 rubrics. The contents of the article from the rubric are obtained through interviews, observation, and literature. There is a definite workflow in making each edition of BioMagz before finally entering the printing and circulation stage. The conclusion is that BioMagz has a magazine form and is published every 3 months and is included as the ideal in-house journal, but in practice, there is still a messy workflow and there are problems in the distribution process. The advice that can be given is to re-evaluate the work and job stages of the editorial and quantity of BioMagz added so that it is spread to all employees.

Keywords: House Journal, In House Journal, Public Relations, Internal Relations

\section{PENDAHULUAN}

Media internal menjadi salah satu cara untuk mempererat hubungan internal dalam perusahaan melalui aspek komunikasi dan bentuk keterbukaan informasi kepada stakeholdernya. Media internal perusahaan merupakan media perusahaan yang diatur dan dijalankan oleh praktisi PR perusahaan yang berada dalam bagian internal. Adapun aplikasi fungsi dan tugas internal PR adalah membantu staf untuk mengerti tentang visi, misi, values serta corporate culture dari organisasi perusahaan. Aktivitas tersebut melibatkan semua hal yang mempengaruhi suasana kerja dan memastikan staf mendapat informasi tentang keputusan penting manajemen (Laksamana, 2010:12). Media Internal atau House Organ (In-House Journal) dipergunakan oleh praktisi Humas/PR untuk keperluan publikasi atau sebagai sarana komunikasi yang ditujukan kepada kalangan terbatas; seperti karyawan, relasi bisnis, nasabah atau konsumen (Ruslan, 2014:218).

Bio Farma merupakan sebuah perusahaan life science yang memproduksi vaksin, anti sera dan blood product bagi masyarakat Indonesia dan juga global dan sebagai perusahaan besar, Bio Farma tentu memiliki jumlah karyawan yang jumlahnya sangat banyak. Dengan jumlah karyawan yang besar tersebut, Bio Farma mengerti bahwa untuk menjalankan perusahaan tentu dibutuhkan dukungan dari karyawan. Bio Farma membangun hubungan internal dengan baik bukan semata-mata ingin mendapat dukungan dan kontribusi, tetapi juga ingin menimbulkan kecintaan karyawan terhadap perusahaan sehingga nantinya dapat tumbuh bersama.

Bio Farma dibantu oleh Bagian Corporate Communications dalam hal pembentukan kegiatan dan ruang untuk publik internal bertemu dan berinteraksi

JURNAL SIGNAL Volume 8, No. 2, Juli 2020, hlm 89-XX| Ilmu Komunikasi - FISIP Universitas Swadaya Gunung Jati p-ISSN: 2580-1090, e-ISSN: 2337-4454 Website: http://jurnal.ugj.ac.id/index.php/Signal 
serta untuk memberikan edukasi akan perusahaan. Corporate communications bertugas untuk membangun saluran komunikasi yang baik bukan hanya terhadap pihak eksternal tetapi juga dalam internal perusahaan kepada seluruh stakeholdernya. Maka dari itu, Bagian Corporate Communications Bio Farma memiliki Seksi Hubungan Internal yang khusus dibentuk untuk mengatur kelancaran komunikasi tersebut.

Salah satu program kerja yang dimiliki oleh Seksi Hubungan Internal ini adalah pengelolaan in house journal yang bernama BioMagz dan berbentuk majalah berukuran A4. Isi dari BioMagz merupakan kumpulan artikel mengenai berita-berita yang menyangkut perusahaan termasuk penghargaan, kegiatan internal, eksternal, peluncuran produk baru dan pemberitaan lainnya tentang perusahaan yang berada di media lain. In house journal ini diterbitkan dalam jangka waktu tiga bulan sekali dan nantinya disebarkan kepada berbagai direktorat Bio Farma.

Media internal perusahaan atau in house journal termasuk kedalam media korporasi-organisasi. In house journal dalam perencanaannya memiliki banyak hal yang harus diperhatikan agar sesuai dengan tujuan awal pembuatan in house journal tersebut dan akhirnya dapat mempengaruhi komunikasi perusahaan sehingga menjadi lebih baik. Berkaitan dengan upaya menghasilkan in house journal yang berkualitas, terdapat komponen kegiatan yang perlu mendapat perhatian dalam pengelolaan in house journal tersebut. Komponen yang dimaksud adalah redaksional, personel dan distribusi dan sirkulasi. (Siregar \& Pasaribu, 2004:160).

Pengegelolaan suatu media komunikasi public relations dalam bentuk cetak tentunya membutuhkan struktur pengurus yang bertugas untuk membuat dan merencanakan akan seperti apa isi dari media tersebut dan apa yang ingin dikomunikasikan. Pengurus dalam hal ini disebut redaksi, yang biasanya terdiri dari pimpinan redaksi yang dibantu oleh wakil pemimpin redaksi kemudian diteruskan oleh managing director atau redaktur pelaksana yang dibantu oleh reporter untuk mencari berita (Ardianto \& Soemirat, 2015:32-33).

$$
\text { Pada bagian corporate }
$$

communications Bio Farma, pengelolaan

JURNAL SIGNAL Volume 8, No. 2, Juli 2020, hlm 89-XX| Ilmu Komunikasi - FISIP Universitas Swadaya Gunung Jati p-ISSN: 2580-1090, e-ISSN: 2337-4454 
media internal atau in house journal dilimpahkan kepada Seksi Hubungan Internal sehingga tersusun dimana pemimpin redaksi tetap dipegang oleh Kepala Bagian Corporate Communications dan wakil pemimpin redaksi oleh Kepala Seksi Hubungan Internal. Sementara itu, Kepala Seksi Hubungan Internal juga merangkap sebagai editor utama dan staff corporate communications lainnya membantu sebagai reporter dan jurnalis. Selanjutnya untuk bagian desain, dibantu oleh staff lain diluar corporate communications yang khusus melalukan desain media in house journal. Komponen kegiatan keredaksian mencangkup kegiatan perencanaan isi, pengumpulan bahan baku informasi, pengelolaan dan penyiapan informasi serta penyuntingan. (Siregar \& Pasaribu, 2004:161).

Perencanaan isi pada tahap awal meliputi informasi apa yang layak disajikan dan bagaimana informasi tersbeut disajikan. Kemudian dua hal tersebut berkembang menjadi suatu perencanaan yang lebih besar meliputi rubrik, topik editorial, materi pelengkap seperti foto bagan dan tabel. (Siregar, 2004:161-162).

Hal utama yang menjadi pertimbangan untuk merencanakan dan menyusun in house journal adalah isi atau konten dari in house journal itu sendiri. In house journal memiliki rubrikasi yang disesuaikan dengan target pembacanya. Melalui rubrikasi tersebut maka akan tercermin informasi yang bersifat informatif, edukatif dan menghibur. Komposisi informasi yang tertera harus mengacu kepada kepentingan perusahaan dan harus sesuai dengan tujuan dari pembuatan media korporasi-organisasi atau in house journal tersebut. Menurut Thomas H. dalam bukunya Public Relations Writing, komposisi isi redaksional yang ideal untuk media internal cetak baik berbentuk newsletter maupun majalah adalah sebagai berikut; (1) 50 persen informasi tentang organisasi, (2) 20 persen informasi karyawan: kondisi lingkungan kerja, peraturan perusahaan, kenaikan gaji, promosi, (3) 20 persen informasi non organisasi: pesaing, konsumen, masyarakat luas dan (4)n10 persen hiburan, opini dan hobi (Hardiman \& Bewinda, 2008:96). 
In house journal Bio Farma memiliki target pembaca karyawan internal yang jumlah cetakannya disesuaikan dengan kebutuhan dan terbit setiap tiga bulan sekali. Gaya bahasa dan format disesuaikan dengan karakteristik pembaca. BioMagz memiliki konten dengan rubrik yang disesuaikan akan informasi tentang artikel dan berita perusahaan, laporan khusus perusahaan, kebijakan, informasi umum yang bersifat edukasi dan informasi yang bersifat menghibur.

In House Journal dalam pengumpulan informasinya membutuhkan bahan-bahan referensi agar dalam membuat suatu artikel dapat berisikan informasi yang valid. Malvin Mencher, dalam bukunya Basic News Writing mengemukakan tiga sumber utama memperoleh informasi untuk berita (Ardianto \& Soemirat, 2010:36);

Pengamatan Langsung, (2) Human source/ narasumber dan (3) Studi pustaka atau menelusuri berbagai laporan, dokumen, bahan referensi lainnya termasuk klipping koran, film, rekaman perpustakaan dan lain sebagainya.

Sebagai sumber pengumpulan data atau bahan, tim corporate communications
Bio Farma dalam pengelolaannya melakukan pengamatan langsung melalui liputan pada setiap acara, mewawancarai narasumber dan melakukan studi pustaka melalui website resmi Bio Farma.

Pengelolaan dan pengerjaan media korporasi-organisasi, dalam hal ini in house journal tentu memerlukan dukungan sejumlah personel yang memiliki pengetahuan dan kemampuan yang memadai. Tetapi, adanya personel belum tentu dapat menghasilkan pekerjaan yang baik tanpa diberikan pemerian kerja atau job description dan pengorganisasian serta mekanisme kerja yang jelas untuk mendukung kelancaran kerja. (Siregar dan Pasaribu, 2004:172).

Pengelolaan in house journal Bio Farma senantiasa dibantu oleh personel yang terdiri dari staff corporate communications Bio Farma itu sendiri selain dari Kepala Seksi Hubungan Internal. Ada kalanya, personel bertambah dengan kehadiran staff magang pada bagian corporate communications.

Pelaksanaan seluruh kegiatan penerbitan media korporasi-organisasi hanya bisa berhasil apabila setiap personel yang berperan dalam kegiatan itu telah

JURNAL SIGNAL Volume 8, No. 2, Juli 2020, hlm 89-XX| Ilmu Komunikasi - FISIP 
mengetahui persis apa saja yang harus dikerjakan dan bagaimana kegiatan itu dikerjakan.

Agar personel bisa bekerja dalam kondisi seperti itu, perlu disusun pemerian tugas (job description) secara jelas. Apa dan bagaimana suatu kegiatan dikerjakan pada tahap tertentu, apa target yang harus dicapai perlu dijabarkan secara rinci. Juga batas waktu untuk menyelesaikan kegiatan tersebut.

Job description pada personel pengelolaan Bio Farma sudah cukup jelas, dengan Kepala Seksi Hubungan Internal sebagai editor utama, diikuti oleh staff corporate communications dan staff magang sebagai reporter dan jurnalis kemudian tim desain untuk membuat desain, format dan layout dari keseluruhan in house journal. Terakhir, Kepala Bagian Corporate Communications sebagai pemimpin redaksi sebagai pihak yang mengoreksi pada saat final dan melakukan persetujuan agar in house journal dapat memasuki proses pencetakan.

Perencanaan kegiatan berdasarkan tahapan kerja yang rinci dan ketat merupakan faktor yang dapat memperlancar kegiatan penerbitan.
Adanya tahapan kerja ini akan mendorong setiap personel menjalankan setiap tugas tepat waktu. Tahapan kerja hanya dapat disusun setelah memiliki pemahaman dan pengenalan atas alur kerja yang dijalankan dalam memperiapkan penerbitan media cetak.

Alur kerja membantu pemahaman bagaimana setiap komponen kegiatan dilaksanakan sebagai bagian dari serangkaian kegiatan dalam proses penerbitan media (Siregar dan Pasaribu, 2004:173). Pada pengelolaan in house journal Bio Farma terdapat tahapan kerja yang sudah dibentuk secara sistematis. Tahapan kerja tersebut mencakup perencanaan, alur pengumpulan konten/isi dan proses pra-cetak hingga tahap pencetakan.

Kegiatan yang dilaksanakan dalam proses produksi mencakup kegiatan pracetak dan pencetakan. Proses pracetak dapat segera dimulai begitu perencanaan isi selesai. Setiap kegiatan pracetak mencakup setiap upaya mendesain tampilan visual media sehingga menarik dipandang, diantaranya mendesain sampul atau cover, rubric dan halaman, penyusunan hasil liputan, penulisan judul

JURNAL SIGNAL Volume 8, No. 2, Juli 2020, hlm 89-XX| Ilmu Komunikasi - FISIP Universitas Swadaya Gunung Jati p-ISSN: 2580-1090, e-ISSN: 2337-4454 
artikel dan pencetakan foto. Sebelum diserahkan ke percetakan, hasil akhir proses pracetak ditampilkan dalam bentuk model jadi (proof) atau dummy. Hasil akhir dari proses pra-cetak kemudian diperiksa kembali apakah hasil telah sesuai dengan kriteria yang telah disepakati sebelumnya. (Siregar dan Pasaribu, 2004:167).

Proses pra-cetak pada penerbitan in house journal Bio Farma banyak dilakukan oleh editor utama yang dibantu oleh staff dan juga oleh tim desain yang terus menerus melakukan koordinasi. Editor utama pada umumnya mengkoreksi konten dan penempatan sementara tim desain bertugas untuk memperbaiki tata letak dan desain sebelum memasuki proses cetak.

Penerbitan house journal bisa dilakukan dalam bentuk elektronik maupun dalam bentuk cetak. Dalam kondisi cetak, proses cetak berarti usaha untuk memproduksi atau menyalin dengan menggunakan suatu alat-alat media atau secara semu dikatakan mencetak (Scheter, dalam Soemirat \& Ardianto, 2010:49). Terdapat beberapa model pencetakan yang dapat digunakan untuk melakukan pencetakan house journal, diantaranya cetak offset, letterpress (cetak tinggi), gravure, screen printing, photogelatin atau collotype, flexography, letterset/dry offset, thermography dan elextrostatic printing (Soemirat \& Ardianto, 2010:4953).

Bagian corporate communications Bio Farma mengedarkan atau mendistribusikan in house journal melalui beberapa cara kepada berbagai direktorat yang ada di Bio Farma dan kepada orangorang yang bersangkutan yang dimuat dalam in house journal.

Tujuan dari dilaksanakannya penelitian ini adalah untuk mengetahui keseluruhan proses pengelolaan media in house journal internal Bio Farma yang dilakukan oleh Seksi Hubungan Internal Corporate Communications yang terdiri dari (1) Untuk mengetahui pengelolaan komponen keredaksian in house journal PT Bio Farma (Persero), (2) Untuk mengetahui pengelolaan komponen personel in house journal PT Bio Farma (Persero), dan (3) Untuk mengetahui pengelolaan komponen produksi dan sirkulasi in house journal PT Bio Farma (Persero). 


\section{METODE PENELITIAN}

Metode penelitian yang digunakan dalam penelitian ini adalah penelitian kualitati dengan data deskriptif. Metode kualitatif digunakan untuk meneliti pada kondisi obyek yang alamiah, dimana peneliti adalah sebagai instrument kunci, teknik pengumpulan data dilakukan secara traingluasi, analisis data bersifat induktif/kualitatif, dan hasil penelitian kualitatif lebih menekankan makna dari pada generalisasi (Sugiyono, 2012:9). Dalam penelitian kualitatif metode yang biasanya dimanfaatkan adalah wawancara, pengamatan, dan pemanfaatan dokumen (Moleong, 2007:5).

Metode ini memungkinkan penulis untuk bebas mengamati objeknya, menjelajah, dan menemukan wawasanwawasan baru sepanjang penelitian Metode deskriptif menitikberatkan pada observasi dan suasana ilmiah yang ada (Ardianto, 2011:118). Dalam pengambilan data, peneliti melakukan wawancara, observasi, dan studi pustaka. Wawancara dilakukan terhadap dua informan kunci yang memang memiliki keterlibatan langsung dalam pengelolaan BioMagz, yaitu terhadap Kepala Bagian Corporate Communications Bio Farma, Nurlaela Arief dan Kepala Seksi Hubungan Internal Corporate Communications Bio Farma, Ratna Djuwita. Observasi partisipatoris dilakukan oleh penulis pertama dalam rangka kegiatan magang kerja selama dua bulan, pada Oktober-November 2018 lalu.

\section{HASIL DAN PEMBAHASAN}

PT Bio Farma (Persero) memiliki praktisi Public Relations untuk membantu perusahaan dalam mencapai tujuannya. Fungsi Public Relations pada Bio Farma dijalankan oleh Bagian Corporate Communications yang berada di bawah Corporate Secretary, dimana Corporate Secretary itu sendiri berada langsung dibawah Direktur Utama yang menjadikan Bagian Corporate Communications sebagai bagian dari Direktorat Utama ${ }^{1}$. Rosady Ruslan (2002:10) dalam bukunya menyatakan bahwa peran Public Relations dalam organisasi atau perusahaan adalah untuk menjalankan fungsi manajemen namun selain itu Public Relations juga

\footnotetext{
${ }^{1}$ Struktur Organisasi PT Bio Farma (Persero) melalui www.biofarma.co.id
} 
berperan sebagai komunikator antara organisasi dengan publiknya, membina relationship, peranan back up management dan membentuk corporate image perusahaan. Selaras dengan hal tersebut, Kepala Bagian Corporate Communications Bio Farma, Nurlaela Arief, menyatakan bahwa Bagian Corporate Communications memiliki peran sebagai komunikator perusahaan sesuai dengan nama bagian yakni komunikasi perusahaan dimana bertugas untuk menghubungkan dan menyampaikan pesan atau informasi perusahaan kepada pihak internal perusahaan yakni karyawan dan stakeholder dan juga kepada pihak eksternal perusahaan seperti konsumen, distributor, vendor dan lainnya agar terbina hubungan baik yang terus terjaga.

Dalam proses komunikasi tersebut, Bagian Corporate Communications menggunakan berbagai media seperti pelaksanaan event, diskusi dan juga melalui berbagai media komunikasi baik cetak, elektronik maupun online. Menurut Nurlaela Arief, Kepala Bagian Corporate
Communications,

Corporate

communications Bio Farma juga senantiasa membantu top management melalui pelaksanaan tugas-tugas yang diberikan seperti membantu pelaksanaan event, management crisis, peluncuran produk baru dan juga membentuk corporate image dengan pesan yang disampaikan melalui media online dan media publikasi lainnya serta dengan memperhatikan dengan cermat bagaimana cara untuk menyampaikan atau mengkomunikasikan pesan secara langsung kepada pihak eksternal sehingga dapat diterima dengan baik ${ }^{2}$.

Sesuai dengan pendapat Rumanti (2005:118), media yang digunakan oleh Bio Farma sebagai sarana komunikasi adalah media cetak, broadcasting media, media sosial, media luar ruang dan melalui pelaksanaan event. Pertama, media yang digunakan oleh Bagian Corporate Communications Bio Farma adalah media cetak dalam bentuk in house journal yang disebarkan kepada publik internalnya yaitu para karyawan dan direksi. Penggunaan media ini bertujuan untuk

\footnotetext{
${ }^{2}$ Wawancara dengan Kepala Bagian Corporate Communications Bio Farma, Nurlaela Arief (Senin, 02/07/18)
}

JURNAL SIGNAL Volume 8, No. 2, Juli 2020, hlm 89-XX| Ilmu Komunikasi - FISIP Universitas Swadaya Gunung Jati p-ISSN: 2580-1090, e-ISSN: 2337-4454 
memberikan informasi kepada karyawan seputar perusahaan dan menjalin komunikasi yang baik dalam lingkup internal. Selanjutnya, Bio Farma juga memiliki media elektronik atau broadcasting media yaitu saluran televisi yang bernama biofarmaid tv yang berisikan tentang liputan kegiatan yang ada di Bio Farma. Bio Farma juga menggunakan Email sebagai sarana komunikasi antar karyawan dan juga sarana komunikasi antar perusahaan dengan karyawan jika ada pengumuman yang ingin disampaikan sekaligus. Bio Farma juga pernah memiliki media radio tetapi kemudian tidak lagi digunakan karena dianggap tidak lagi efektif. Selain itu, menurut Kepala Seksi Hubungan Internal, Bio Farma juga menggunakan media luar ruang seperti poster, mading, reklame, spanduk, billboard untuk kepentingan publikasi dan penyaluran komunikasi kepada publiknya ${ }^{3}$.

Bio Farma juga senantiasa melaksanakan berbagai event yang banyak dikelola oleh Bagian Corporate Communications sebagai sarana komunikasi antara perusahaan dengan publik internal maupun eksternalnya. Event yang diadakan oleh Bagian Corporate Communications biasanya berupa special event seperti acara HUT Bio Farma, peluncuran produk vaksin baru, open house, coffee morning semuanya menyangkut dengan proses komunikasi antara perusahaan dengan publik internal maupun eksternal.

Pengelolaan media internal InHouse Journal yang umumnya disusun dan dikelola oleh Public Relations atau Bagian Corporate Communications dilakukan oleh Kepala Seksi Hubungan Internal dari Corporate Communications yang memiliki tim desain khusus. In house Journal disusun berdasarkan berita-berita yang berhubungan dengan Bio Farma, baik yang dikeluarkan oleh media ataupun pihak internal perusahaan.

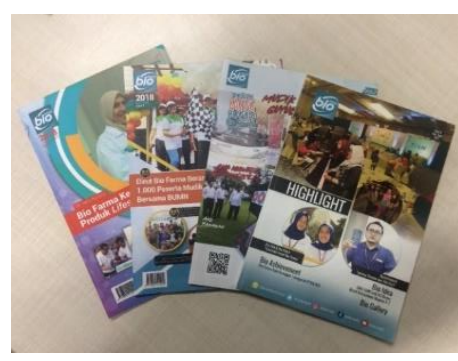

Sumber: Foto penulis

\section{Gambar 1 House Journal Bio Farma}

\footnotetext{
${ }^{3}$ Wawancara dengan Kepala Seksi Hubungan Internal Corporate Communications Bio Farma, Ratna Djuwita (Rabu, 04/07/18)
}

JURNAL SIGNAL Volume 8, No. 2, Juli 2020, hlm 89-XX| Ilmu Komunikasi - FISIP Universitas Swadaya Gunung Jati p-ISSN: 2580-1090, e-ISSN: 2337-4454 
Sesuai dengan pernyataan Ratna Djuwita, Kepala Seksi Hubungan Internal, media in house journal ini diusung oleh Kepala Bagian Corporate Communications terdahulu dan mulai dicetak dan disebar kepada seluruh karyawan mulai tahun $2008^{4}$. Nama dari in house journal Bio Farma adalah BioMagz. Tujuan utama dari penyusunan BioMagz ini adalah untuk memberikan update informasi kepada karyawan mengenai halhal seputar perusahaan. Kegiatan apa saja yang dilakukan perusahaan, pencapaian perusahaan, kerja sama yang dilakukan dan pemberitaan seperti apa yang ditulis oleh media terkait perusahaan sehingga tidak hanya informasi yang didapat, tetapi juga menumbuhkan rasa cinta dan bangga karyawan terhadap perusahaan. Selain itu, masih menurut beliau, penyusunan BioMagz juga dilakukan untuk menginspirasi para karyawan untuk terus lebih maju dan mengembangkan dirinya melalui ide-ide kreatif dan kontribusi pada perusahaan $^{5}$.

\footnotetext{
4 ibid

${ }^{5}$ Wawancara dengan Kepala Seksi Hubungan Internal Corporate Communications Bio Farma, Ratna Djuwita (Selasa, 10/07/18)
}

Menurut Ruslan, (2014:200), media internal humas memiliki beberapa jenis diantaranya adalah majalah, tabloid dan newsletter. In house journal yang dimiliki oleh Bio Farma yakni BioMagz merupakan media cetak internal yang berbentuk majalah dengan dimensi A4 $(21 \times 29.7 \mathrm{~cm})$ dan memiliki 30-50 halaman, tergantung kepada kegiatan yang terjadi pada edisi BioMagz tersebut terbit yang kemudian akan menjadi isi dari BioMagz tersebut.

Pemilihan majalah sebagai bentuk BioMagz dikarenakan bentuk majalah dianggap sebagai bentuk in house journal yang lazim di semua Badan Usaha Milik Negara (BUMN), mengingat Bio Farma adalah bagian dari BUMN. Bentuk cetak seperti majalah sebagai bentuk dari in house journal adalah syarat Kriteria Penilaian Kerja Unggul (KPKU), ketentuan dari BUMN bahwa setiap BUMN wajib memiliki in house journal yang berbentuk majalah. Selain itu, Bio Farma juga pernah memiliki in house journal dalam bentuk elektronik yaitu

JURNAL SIGNAL Volume 8, No. 2, Juli 2020, hlm 89-XX| Ilmu Komunikasi - FISIP Universitas Swadaya Gunung Jati p-ISSN: 2580-1090, e-ISSN: 2337-4454 
melalui penggunaan aplikasi yang dapat diunduh melalui app store dalam smartphone. Tetapi, menurut Ratna Djuwita, dikarenakan pengadaan efisiensi biaya maka in house journal dalam bentuk elektronik ditiadakan dan hanya tersedia dalam bentuk cetak ${ }^{6}$.

Menurut Ruslan (2014:202) terdapat beberapa fungsi in house journal pada umumnya yang kemudian disesuaikan dengan fungsi in house journal Bio Farma atau BioMagz sesuai hasil wawancara dengan Kepala Seksi Hubungan Internal, Ratma Djuwita (Kamis, 18/10/18). Fungsi-fungsi tersebut diantaranya; (1) Sebagai media hubungan komunikasi internal dan eksternal. BioMagz memiliki fungsi utama sebagai sarana komunikasi internal perusahaan dan diedarkan secara gratis di internal perusahaan. BioMagz berfungsi untuk menyampaikan informasi mengenai seluruh kegiatan yang ada di Bio Farma kepada karyawannya dalam bentuk berita, artikel dan foto. (2) Sebagai ajang komunikasi khusus antar karyawan. BioMagz merupakan in house journal yang khusus untuk pihak internal sehingga memang berfungsi sebagai ajang komunikasi kepada karyawan dan antar karyawan, dimana komunikasi antar karyawan terjadi melalui beberapa rubric khusus yang diisi oleh karyawan lain bertujuan untuk memberikan inspirasi kepada karyawan lain. (3) Sebagai sarana media untuk "pelatihan dan pendidikan" dalam bidang tulis menulis bagi karyawan serta staff Humas/PR. BioMagz tidak berfungsi sebagai media pelatihan dan pendidikan bidang tulis menulis bagi karyawan karena penyusunan hanya dilakukan oleh Seksi Hubungan Internal Corporate Communications Bio Farma. Sebelumnya, karyawan yang ingin berkontribusi dan memiliki kemampuan menulis dapat dituangkan kedalam BioMagz. Tetapi, seiring berjalannya waktu sistem itu dinilai tidak efektif karena karyawan memiliki kendala pekerjaan lain sehingga tidak ada waktu untuk menulis sementara BioMagz memiliki waktu tertentu untuk terbit. Sehingga pelatihan untuk menulis mungkin hanya berlaku bagi staff corporate communications yang berkontribusi menjadi reporter dalam pengumpulan bahan BioMagz.

\section{${ }^{6}$ ibid}

JURNAL SIGNAL Volume 8, No. 2, Juli 2020, hlm 89-XX| Ilmu Komunikasi - FISIP Universitas Swadaya Gunung Jati p-ISSN: 2580-1090, e-ISSN: 2337-4454 Website: http://jurnal.ugi.ac.id/index.php/Signal 
Terdapat nilai tambah (value added) bagi departemen Humas/PR. BioMagz memberikan nilai tambah (value added) bagi Bagian Corporate Communications utamanya karena penerbitan in house journal dalam bentuk cetak ini merupakan syarat utama KPKU BUMN sehingga jika hasil dari in house journal berkualitas dapat turut tercermin citra baik bagi Bagian Corporate Communications.

Menurut Rumanti (2005:121-122), terdapat pihak-pihak yang pada umumnya sering menjadi publik dari house journal, diantaranya distributor, konsumen, pihakpihak yang secara langsung berhubungan dengan perusahaan/organisasi namun memiliki kaitan tertentu dan potensi yang penting, opinion leader, pelanggan tetap dan calon konsumen. Namun, BioMagz sebagai in house journal Bio Farma hanya menargetkan karyawan internal dan direksi sebagai publiknya. Tetapi, Ratna Djuwita menyampaikan bahwa tidak menutup kemungkinan untuk publik eksternal untuk mengakses BioMagz jika pihak eksternal tersebut berkunjung ke Bio Farma sebagai tamu perusahaan karena
BioMagz disimpan di ruang tamu perusahaan $^{7}$

In House Journal sebagai salah satu media internal perusahaan tentunya harus disusun dan dikelola dengan baik, hal ini dikarenakan in house journal dapat menjadi salah satu media penyaluran informasi terkait berbagai kegiatan dan pencapaian perusahaan, sebagai bentuk keterbukaan perusahaan terhadap karyawannya, serta sebagai media untuk menyalurkan aspirasi dan diharapkan dapat menginspirasi karyawan untuk berkembang. Penerbitan dan penyebaran in house journal merupakan salah satu taktik yang dilakukan oleh PR untuk membentuk hubungan internal yang baik antara karyawan dengan perusahaan, untuk itu dalam pengelolaan in house journal harus dilakukan dengan baik dan teliti agar tujuan dan pesan dapat tersampaikan dengan baik dan tidak menimbulkan opini lain yang dapat merusak hubungan dengan karyawan dan citra perusahaan di mata karyawannya.

Pengelolaan in house journal juga dapat dijadikan acuan dalam proses

\footnotetext{
${ }^{7}$ Wawancara dengan Kepala Seksi Hubungan Internal Corporate Communications Bio Farma, Ratna Djuwita (Kamis, 18/10/18)
}

JURNAL SIGNAL Volume 8, No. 2, Juli 2020, hlm 89-XX| Ilmu Komunikasi - FISIP Universitas Swadaya Gunung Jati p-ISSN: 2580-1090, e-ISSN: 2337-4454 
menyusun dan mengatur strategi komunikasi internal, karena in house journal yang dibuat tidak hanya disebarkan dalam bentuk cetak tetapi juga dalam bentuk elektronik yang ditampilkan pada corporate portal, dimana merupakan sebuah website khusus internal tempat penyaluran informasi bagi seluruh karyawan. Dengan adanya in house journal dalam corporate portal tersebut, dapat terpantau jumlah orang yang mengakses in house journal dan informasi lainnya sehingga bisa menjadi salah satu tolak ukur efektivitas media internal dalam membangun hubungan internal perusahaan.

Pengelolaan in house journal Bio Farma yaitu BioMagz memerlukan susunan redaksi agar pengelolaan dapat berjalan dengan baik, terstruktur dan menghasilkan in house journal yang berkualitas. Berikut adalah susunan redaksi resmi dari BioMagz; (1) Pemimpin Redaksi yaitu Kepala Bagian Corporate Communications - Nurlaela Arief, (2) Wakil Pemimpin Redaksi/Editor Utama/Reporter yaitu Kepala Seksi
Hubungan Internal - Ratna Djuwita, (3) Editor/Reporter yaitu Staff Corporate Communications, (4) Reporter yaitu Staff Corporate Communications, dan terakhir (5) Desain yaitu Tim Desain khusus diluar Corporate Communications.

BioMagz berisi tentang berita, berbagai jenis artikel, galeri kegiatan, kebijakan perusahaan, visi misi dan prinsip-prinsip yang ditanamkan perusahaan. Selain itu, house journal menampilkan aspek-aspek GCG (Good Corporate Governance) dan sebagai bagian dari BUMN, house journal Bio Farma juga harus menampilkan kegiatan BUMN sebagai tanda bahwa Bio Farma mendukung program tersebut. Isi dari berita dan artikel yang akan dimuat dalam house journal dipilih secara teliti. Kriteria berita dan artikel tersebut tidak boleh mengandung hal-hal yang berbau politik atau yang dapat membentuk opini karyawan secara negatif terhadap perusahaan ${ }^{8}$. Berita dan artikel yang dimuat harus netral dan berhubungan dengan perusahaan ataupun karyawan, atau berhubungan dengan kesehatan

\footnotetext{
${ }^{8}$ Pernyataan Kepala Seksi Hubungan Internal Corporate Communications Bio Farma, Ratna Djuwita (Jumat, 13/10/18).
}

JURNAL SIGNAL Volume 8, No. 2, Juli 2020, hlm 89-XX| Ilmu Komunikasi - FISIP Universitas Swadaya Gunung Jati p-ISSN: 2580-1090, e-ISSN: 2337-4454 
secara umumnya sehubungan dengan perusahaan yang memang berkaitan dengan bidang kesehatan atau peningkatan kualitas hidup.

BioMagz terdiri dari 10 rubrik, diantaranya; (1) Bio News: Berisi tentang berita tentang Bio Farma atau berita yang memuat Bio Farma pada umumnya baik yang dipublikasikan oleh media internal ataupun eksternal, (2) Bio Health: Berisi tentang artikel umum yang memuat informasi kesehatan, penyakit, imunisasi dan lain sebagainya, (3) Bio CSR: Berisi tentang kegiatan CSR yang dilakukan oleh Bio Farma, (4) Bio Lapsus: Berisi tentang laporan khusus tentang apa yang terjadi dalam internal Bio Farma seperti pengangkatan direksi dan komisaris, ulang tahun perusahaan, sambutan direktur utama dan lain sebagainya, (5) Bio Idea: Berisi tentang artikel inspiratif dari karyawan Bio Farma untuk memberikan inspirasi dan ide-ide pemikiran baru bagi para pembaca, (6) Bio Achievement: Berisi tentang pencapaian-pencapaian dan penghargaan yang diterima oleh Bio Farma baik nasional, pemerintah maupun internasional, (7) Bio Employee: Berisi tentang artikel mengenai karyawan Bio
Farma yang berprestasi, memiliki sesuatu yang berbeda dari yang lain dengan tujuan untuk menginspirasi karyawan lainnya sebagai pembaca, (8) Bio Event: Berisi tentang hasil liputan event atau kegiatan yang diselenggarakan oleh Bio Farma baik dengan cangkupan internal ataupun eksternal, (9) Bio Rohani: Berisi tentang hal-hal religius, mencangkup agama dan kegiatan DKM Masjid An Nuur Bio Farma dan (10) Galeri Foto.

Rubrik-rubrik diatas kemudian dilengkapi oleh sambutan dari direksi dan redaksi, susunan redaksi, daftar isi, kebijakan perusahaan, visi misi, $G C G$ dan galeri yang memuat foto-foto kegiatan selama tiga bulan sesuai edisi dari house journal tersebut. BioMagz terbit sebanyak 4 kali dalam satu tahun atau tiga bulan sekali per edisinya.

Meninjau dari rubrik-rubrik diatas beserta penjabarannya, dapat diketahui rubrik yang berisikan tentang informasi perusahaan sebanyak 5 rubrik yaitu BioEvent, BioNews, BioLapsus, BioCSR dan BioAchievement. Selanjutnya, rubrik yang berisikan informasi karyawan sebanyak 2 rubrik yaitu BioIdeas dan BioEmployee. Kemudian, rubrik yang 
berisikan informasi non-organisasi sebanyak 2 rubrik yaitu BioHealth dan BioRohani. Terakhir, rubrik yang berisikan hiburan atau opini yaitu galeri foto kegiatan dan informasi tambahan berupa pencapaian yang diraih oleh karyawan. Bisa disimpulkan dari uraian diatas bahwa dari 10 rubrik terdapat 5 rubrik yang menyangkut informasi perusahaan yaitu sebesar 50 persen, 2 rubrik informasi karyawan sebesar 20 persen, 2 rubrik non-organisasi sebesar 20 persen dan terakhir terdapat 1 rubrik informasi atau hiburan sebesar 10 persen. Jika disesuaikan dengan pernyataan Thomas H. Bivnis dalam bukunya Public Relations Writing, dimana ia menyatakan tentang komposisi isi redaksional yang ideal untuk media internal cetak baik berbentuk newsletter maupun majalah (Hardiman \& Bewinda, 2008:96), maka dapat disimpulkan bahwa BioMagz telah memiliki susuna rubrik dan isi yang ideal.

Selain itu, terdapat pendapat lain mengenai rubrik standar dari in house journal menurut Hardiman \& Bewinda (2008:99) dan jika dibandingkan dengan komposisi tersebut, BioMagz belum bisa disebut sebagai in house journal yang memenuhi standar dikarenakan hanya memiliki beberapa dari rubrik yang dijabarkan seperti daftar isi, masthead, editorial, laporan utama dan artikel perusahaan. Sementara itu, BioMagz tidak memiliki rubrik untuk surat pembaca dan iklan. Hal ini tentu bukan tanpa alasan, menurut Ratna Djuwita, BioMagz merupakan in house journal yang hanya diedarkan untuk kalangan internal dan tidak diperjual belikan sehingga tidak dirasa perlu untuk memasang iklan. Pemilihan isi rubrik beserta nama dari rubrik pada BioMagz disesuaikan dengan kebutuhan pembaca, dengan keadaan perusahaan dan kegiatan yang ada di perusahaan sehingga dalam setiap edisinya bukan tidak mungkin bahwa rubrik yang ada berbeda-beda, tetapi perbedaan tersebut tidak mengartikan perubahan yang besar dalam setiap edisi BioMagz ${ }^{9}$.

\footnotetext{
${ }^{9}$ Wawancara dengan Kepala Seksi Hubungan Internal Corporate Communications Bio Farma, Ratna Djuwita (Kamis, 18/10/18).
}

JURNAL SIGNAL Volume 8, No. 2, Juli 2020, hlm 89-XX| Ilmu Komunikasi - FISIP Universitas Swadaya Gunung Jati p-ISSN: 2580-1090, e-ISSN: 2337-4454 


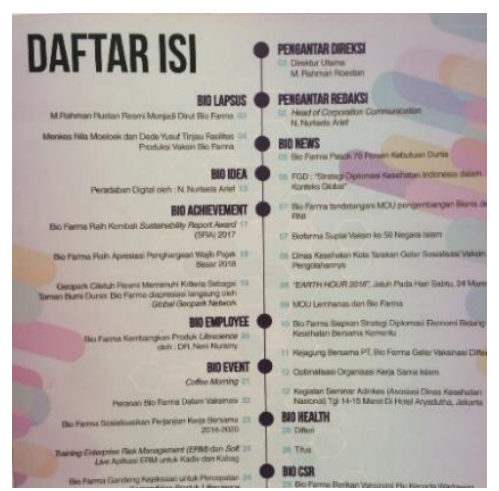

\section{Gambar 2 Contoh daftar isi dan rubrik-rubrik yang ada dalam BioMagz}

Berita dan artikel yang dimuat pada BioMagz berasal dari beberapa sumber, utamanya berasal dari berita yang sudah dipublikasikan melalui media online yang dimiliki oleh perusahaan seperti website, Facebook dan Instagram. Berita dan press release yang diambil kemudian dimuat kedalam BioMagz biasanya hanya mengisi rubrik BioNews, BioCSR dan sebagian dari BioEvent.

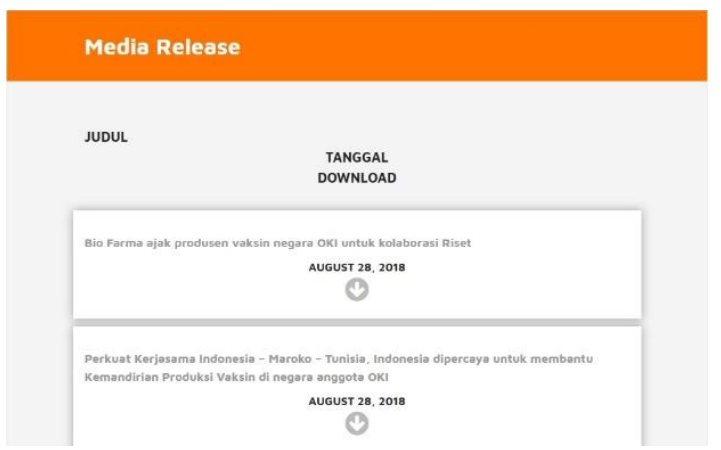

Sumber: www.biofarma.co.id

\section{Gambar 3 Release dan Berita pada website Bio Farma}

Selain melalui media online milik perusahaan, pemberitaan mengenai perusahaan juga bisa diambil melalui media eskternal yang meliput tentang kegiatan perusahaan. Jika berita belum dimuat oleh kedua media tersebut, maka penulis membuat sendiri berita yang materinya dikumpulkan melalui peliputan kegiatan yang telah dilakukan terlebih dahulu. Selain itu, khusus untuk artikel yang bersifat informasi umum seperti kesehatan dan religi pada rubric BioHealth dan BioReligi, penulis bisa mengambil dari artikel yang telah dimuat atau telah beredar sebelumnya. Poin tersebut sesuai dengan poin studi pustaka dalam sumber utama memperoleh informasi untuk berita menurut Malvin Mencher yang dimuat dalam Ardianto \& Soemirat (2010:36).

Selanjutnya untuk pembuatan artikel event dan laporan khusus, penulis akan membuat artikel berdasarkan hasil liputan yang dilaksanakan pada saat event itu berlangsung. Kegiatan tersebut dilakukan untuk mengisi rubrik BioLapsus dan sisa dari BioEvent. Poin ini memenuhi poin observasi menurut Malvin Mencher.

Terakhir, poin wawancara dipenuhi dengan pemenuhan rubrik Bio Ideas dan

JURNAL SIGNAL Volume 8, No. 2, Juli 2020, hlm 89-XX| Ilmu Komunikasi - FISIP Universitas Swadaya Gunung Jati p-ISSN: 2580-1090, e-ISSN: 2337-4454 
Bio Employee yang dalam pengumpulan datanya dilakukan dengan wawancara kepada karyawan yang dirasa sesuai untuk mengisi rubrik tersebut.

Pengelolaan BioMagz tentu memerlukan personel dengan pengetahuan dan kemampuan yang mumpuni dalam proses penyusunannya. Selama penulis melakukan penelitian, perencanaan, pengumpulan bahan, pembuatan berita dan artikel dilakukan oleh penulis dengan bantuan Kepala Seksi Hubungan Internal sebagai pihak yang mengawasi dan mengoreksi. Selain itu, penulis juga dibantu oleh rekan lain dalam proses peliputan kegiatan sebagai tim dokumenasi. Setelah bahan siap sedia, barulah rancangan BioMagz diserahkan sepenuhnya kepada tim desain untuk dibuat layout dan final desain.

Memastikan pelaksanaan pembuatan in house journal BioMagz sejatinya merupakan tugas dan job description dari Kepala Seksi Hubungan Internal Corporate Communications Bio Farma ${ }^{10}$. Untuk itu, Kepala Seksi Hubungan Internal, Ibu Ratna Djuwita melimpahkan kegiatan pengelolaan BioMagz kepada penulis. Sehingga job description dari penulis dalam pengelolaan BioMagz ini adalah membuat perencanaan isi dari BioMagz, melakukan media monitoring sebagai bahan untuk artikel isi BioMagz, melakukan liputan sebagai bahan untuk artikel isi BioMagz, melakukan wawancara sebagai bahan untuk artikel isi BioMagz, membuat tulisan artikel untuk isi rubrik BioMagz hasil wawancara dan liputan dan melakukan penyusunan artikel dan rubrik untuk dikumpulkan pada tim desain.

Selain itu, Kepala Seksi Hubungan Internal juga bertugas untuk mengoreksi segala pekerjaan yang dilakukan oleh penulis dan melakukan pemeriksaan akhir terhadap BioMagz yang telah memasuki tahap pra-cetak. Kemudian, tim desain yang nanti akan membuat layout dan keseluruhan desain dan tampilan dari BioMagz hingga proses percetakan. Terakhir, Kepala Bagian Corporate Communications bertugas sebagai pihak yang menyetujui apakah BioMagz yang

\footnotetext{
${ }^{10}$ Jobdesc Kepala Seksi Hubungan Internal dari Jobdesc Book Corporate Communications Bio Farma
}

JURNAL SIGNAL Volume 8, No. 2, Juli 2020, hlm 89-XX| Ilmu Komunikasi - FISIP Universitas Swadaya Gunung Jati p-ISSN: 2580-1090, e-ISSN: 2337-4454 
dibuat telah layak cetak dan siap disebarkan atau belum.

Menurut Siregar dan Pasarbu (2004:173), terdapat alur kerja yang dapat digunakan dalam pengelolaan dan penyusunan in house journal yang terdiri dari perencanaan - pengumpulan bahan penyiapan bahan - produksi - pencetakan - sirkulasi - pembaca kemudian kembali lagi pada proses perencanaan untuk edisi selanjutnya. Prakteknya, alur tahapan kerja yang dilakukan oleh penulis tidak jauh beda dengan apa yang diusulkan oleh Siregar dan Pasaribu diatas.

Langkah pertama yang dilakukan penulis adalah membuat perencanaan untuk edisi baru BioMagz. Memasuki triwulan baru, BioMagz edisi sebelumnya yakni Edisi 7 bulan April-Juni memasuki tahap evaluasi, dilengkapi kembali dan proses percetakan. Setelah dicetak, BioMagz kemudian disebar ke berbagai divisi dan bagian yang ada dalam perusahaan. Sementara untuk BioMagz edisi selanjutnya yakni Edisi 8 bulan JuliSeptember mulai dipersiapkan.

\section{Bagan 1 Tahapan Kerja dalam Pengelolaan BioMagz}

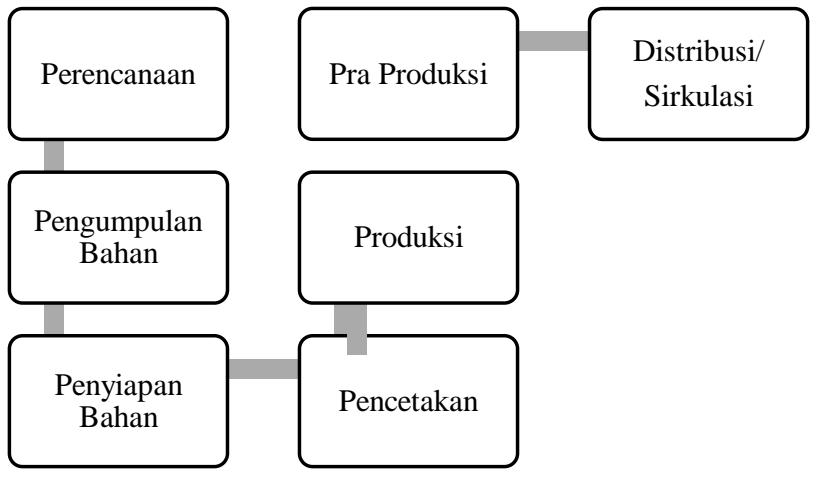

Pengumpulan data diawali dengan membuat perencanaan isi BioMagz dalam Microsoft Excel, sesuai dengan rubriknya. Kemudian, setiap kegiatan yang diselenggarakan oleh atau di Bio Farma diisikan kedalam daftar rubrik yang sudah dibuat sebelumnya. Kegiatan tersebut dipisahkan sesuai kategori, baik itu berita, CSR, event, laporan khusus dan lain sebagainya. Setelah itu dilanjutkan dengan kegiatan media monitoring tetapi hanya media internal saja yang diamati seperti website, Facebook dan Instagram yang sekiranya biasa mempublikasi konten berita ataupun press release. Berita yang diambil hanya merupakan berita yang memuat kegiatan pada bulan edisi house

JURNAL SIGNAL Volume 8, No. 2, Juli 2020, hlm 89-XX| Ilmu Komunikasi - FISIP Universitas Swadaya Gunung Jati p-ISSN: 2580-1090, e-ISSN: 2337-4454 
journal yakni pada bulan Juli-Agustus 2018

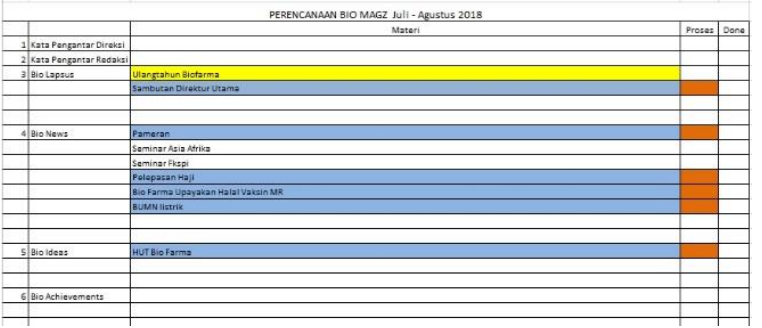

Gambar 4 Jadwal Perencanaan House Journal

Setelah semua data dan bahan terkumpul, data dikumpulkan kedalam satu folder, kemudian selama pengumpulan data, beberapa rubrik yang telah selesai dibuat dan diedit kemudian dikumpulkan atau di submit kepada kepala seksi bagian internal untuk dilakukan proses revisi dan final edit. Setelah dari kepala seksi kemudian artikel dan berita untuk isi rubrik BioMagz dikirim kepada tim desain untuk disusun dan dilakukan proses desain sehingga sedikit demi sedikit menjadi satu kesatuan majalah. Setelah BioMagz mendekati lengkap, dilakukan revisi berkala terhadap setiap update dilakukan. Revisi ini meliputi kesalahan penulisan atau typo, ilustrasi atau desain yang dipilih, gambar yang digunakan dan kesalahan cetak lainnya. Proses ini berlangsung secara kontinuitas, terus menerus sehingga BioMagz siap dicetak. Kemudian dilakukan pengecekan daftar isi, apakah rubrik sudah siap terisi semua atau belum dan apakah jumlah isi rubrik sudah cukup atau belum. Jika belum, maka dilakukan lagi pembuatan artikel melalui peliputan dan wawancara atau melakukan review terhadap kegiatankegiatan yang telah dilakukan sebelumnya namun belum terdapat press release atau belum dijadikan sebagai materi artikel.

BioMagz yang telah siap cetak kemudian dicetak dalam bentuk dummy untuk dilakukan proses pengecekan tahap akhir dan revisi. Pada tahap ini dilakukan pengecekan dan koreksi menyeluruh utamanya terhadap konten dan desain. Jika dirasa sudah memenuhi syarat dan memuaskan, BioMagz dalam bentuk dummy diserahkan kepada Kepala Bagian Corporate Communication untuk disetujui pencetakannya.

Terdapat beberapa teknik untuk melakukan pencetakan in house journal dalam bentuk majalah, menurut Soemirat \& Ardianto (2010:49), teknik tersebut diantaranya cetak offset, letterpress (cetak tinggi), gravure, screen printing, photogelatin atau collotype, flexography, letterset/dry offset, thermography dan

JURNAL SIGNAL Volume 8, No. 2, Juli 2020, hlm 89-XX| Ilmu Komunikasi - FISIP Universitas Swadaya Gunung Jati p-ISSN: 2580-1090, e-ISSN: 2337-4454 
elextrostatic printing. Diantara teknik pencetakan tersebut, menurut Kepala Seksi Hubungan Internal mengatakan bahwa teknik yang dipilih oleh Bio Farma untuk mencetak BioMagz adalah dengan menggunakan teknik offset ${ }^{11}$, kendati demikian ia lebih lanjut menyatakan bahwa ia tidak memiliki pengetahuan lebih terkait teknik pencetakan karena hal tersebut diserahkan sepenuhnya kepada tim desain. Tetapi, untuk mencetak BioMagz dilakukan menggunakan mesin cetak milik perusahaan dan bukan melalui pihak ketiga. BioMagz yang telah selesai dicetak kemudian diberikan kepada bagian corporate communications untuk diperiksa kembali sebelum diedarkan. Jika terdapat kesalahan, maka BioMagz akan dikembalikan kepada percetakan dan tim desain untuk diperbaiki, sama halnya bila kesalahan terjadi setelah proses sirkulasi dan distribusi, maka BioMagz tersebut akan ditarik dan dikumpulkan menjadi satu sebelum dikembalikan pada percetakan dan tim desain. Setiap satu edisi BioMagz untuk saat ini dicetak sebanyak 10 eksemplar yang kemudian

dibagikan pada seluruh direksi dan beberapa direktorat yang ada di Bio Farma. BioMagz yang telah dicetak kemudian disebarkan oleh penulis dan Kepala Seksi Hubungan Internal kepada setiap ruangan direksi, ruang penerimaan tamu dan direktorat yang bersangkutan dengan isi dari edisi BioMagz yang baru terbit. BioMagz ini tidak disebarkan kepada seluruh direktorat karena adanya efisiensi biaya, sehingga bagi karyawan yang ingin membaca bisa mendatangi ruang tamu atau meminta langsung kepada Bagian Corporate Communications Bio Farma.

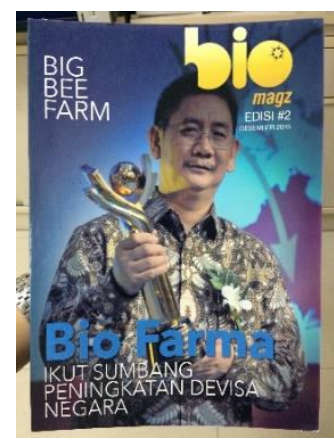

Sumber: Koleksi Biofarma

Gambar 5 BioMagz dari edisi lama yang tersimpan di ruang informasi publik (ruang tamu) Bio Farma

Pada saat dilakukan penelitian, BioMagz untuk edisi 7 dan 8 masing-

\footnotetext{
${ }^{11}$ Wawancara dengan Kepala Seksi Hubungan Internal Corporate Communications Bio Farma, Ratna Djuwita (Kamis, 18/10/18)
}

JURNAL SIGNAL Volume 8, No. 2, Juli 2020, hlm 89-XX| Ilmu Komunikasi - FISIP Universitas Swadaya Gunung Jati p-ISSN: 2580-1090, e-ISSN: 2337-4454 
masing dicetak sebanyak 10 eksemplar untuk keseluruhan perusahaan. 10 eksemplar tersebut di bagikan kepada semua jajaran direksi, ruang tamu, bagian corporate communications dan pada pihak yang bersangkutan. Pihak yang bersangkutan disini biasanya adalah staff Bio Farma yang sebelumnya telah dijadikan narasumber dan artikelnya dimuat pada BioMagz edisi terkait. Hal ini dikarenakan terdapat efisiensi biaya seperti yang disebutkan diatas. Namun, selain itu, penulis merasa persebaran informasi bahwa terbitnya BioMagz sendiri belum berjalan dengan baik karena masih banyak karyawan yang tidak mengetahui adanya BioMagz dan tidak pernah mendapatkannya. Hal ini tentu berkaitan dengan jumlah BioMagz yang memang sangat minim jika dibandingkan dengan jumlah karyawan Bio Farma yang merupakan sebuah perusahaan besar, tetapi hal itu bisa diatasi jika komunikasi berjalan dengan baik. Hal ini bisa diatasi dengan menyebarkan pengumuman pada madding atau email perusahaan jika BioMagz yang baru telah terbit dan dimana untuk mendapatkannya sehingga jumlah yang sedikit pun bukan menjadi masalah untuk persebaran informasi dan sarana komunikasi internal perusahaan melalui house journal.

\section{SIMPULAN}

House Journal BioMagz Terbit setiap 3 bulan sekali, dalam penyusunannya, house journal melalui tahap pengumpulan data, berupa berita dan artikel yang berisi tentang Bio Farma atau ada kaitannya dengan Bio Farma di mana artikel atau berita yang dimuat pada house journal tidak boleh membentuk opini karyawan terhadap politik dan menyebabkan provokasi. Data yang dikumpulkan berasal dari berita atau release dan artikel yang sudah ada atau bisa juga merupakan hasil liputan dan wawancara yang kemudian melalui tahap transkrip dan penulisan sehingga menjadi satu artikel yang layak. Tahapan selanjutnya adalah melakukan penyusunan house journal. Tahapan ini dilakukan dengan mengumpulkan materi atau data yang telah ada kemudian di submit kepada kepala seksi bagian internal untuk direvisi dan melalui tahap final edit. Selanjutnya data tersebut diteruskan kepada tim desain untuk disusun dan dijadikan satu kesatuan majalah, hasil yang sudah jadi direvisi dan

JURNAL SIGNAL Volume 8, No. 2, Juli 2020, hlm 89-XX| Ilmu Komunikasi - FISIP Universitas Swadaya Gunung Jati p-ISSN: 2580-1090, e-ISSN: 2337-4454 
kemudian ditambahkan dengan materi yang baru. Proses ini berlangsung terusmenerus atau kontinuitas hingga semua data lengkap. Selanjutnya setelah lengkap, house journal melalui tahap cetak yang menghasilkan dummy untuk dilakukan pengecekan ulang. Setelah dirasa baik, maka house journal dicetak dengan jumlah tertentu dan disebarkan ke seluruh divisi yang ada di Bio Farma.

Kegiatan pengelolaan house journal yang dilakukan oleh kepala seksi bagian internal corporate communication Bio Farma telah terstruktur dengan cukup baik. Hal-hal yang sekiranya penting, informatif dan dapat menginspirasi karyawan telah dimuat dengan baik. Terdapat beberapa hal yang memang perlu untuk diperbaiki, seperti proses penyusunan House Journal dalam tahap finalisasi dan revisi diharapkan lebih cepat agar tidak menghambat proses pencetakan, sebaiknya lebih banyak dibuat beritaberita dan artikel yang berbeda dan sama sekal baru dengan yang telah dipublikasikan sebelumnya. Perlu ada rubrik hiburan agar pembaca terhibur dan menantikan house journal edisi berikutnya. Jadwal perencanaan house journal belum dibuat hingga house journal hampir rampung sehingga banyak terdapat rubrik yang jumlah isinya belum lengkap ataupun terlewat. Sebaiknya diusahakan untuk membuat jadwal perencanaan di awal triwulan baru. Jumlah house journal yang dicetak sebaiknya ditambah atau paling tidak dikomunikasikan dengan baik terkait penerbitan house journal dan dimana bisa mendapatkannya.

\section{DAFTAR PUSTAKA}

Ardianto, Elvinaro. 2011. Handbook of Public Relation. Jakarta: Simbiosa Rekatama Media.

Hardiman, Ima dan Rike Bewinda. 2008. Inhouse Magazine. Jakarta: Gagas Ulung.

Laksamana, Agung. 2010. Internal Public Relations. Jakarta: Republika.

Moleong, Lexy. 2007. Metode Penelitian Kualitatif. Bandung: PT Remaja Rosdakarya.

Rumanti, Sr. Maria Assumpta. 2005. Dasardasar Public Relations: Teori dan Praktik. Jakarta: Grasindo.

Ruslan, Rosady. 2002. Manajemen Humas dan Komunikasi, Konsepsi, dan Aplikasi. Jakarta: PT. Raja Grafindo Persada.

Ruslan, Rosady. 2014. Manajemen Public Relations dan Media Komunikasi (Edisi Revisi). Jakarta: PT. Rajawali Pers.

Siregar, Ashadi dan Rondang Pasaribu. 2004. Bagaimana Mengelola Media Korporasi-Organisasi. Yogyakarta: Kanisius.

JURNAL SIGNAL Volume 8, No. 2, Juli 2020, hlm 89-XX| Ilmu Komunikasi - FISIP 
Soemirat, Soleh. Elvinaro Ardianto. 2010.

Dasar-dasar Public Relations.

Bandung: PT Remaja Rosdakarya.

Sugiyono. 2012. Metode Penelitian

Kuantitatif Kualitatif dan $R \& D$.

Bandung: Alfabeta.

JURNAL SIGNAL Volume 8, No. 2, Juli 2020, hlm 89-XX| Ilmu Komunikasi - FISIP 